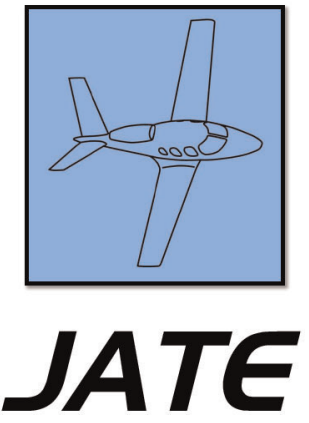

Journal of Aviation Technology and Engineering 11:1 (2022) 1-10

\title{
Assessing Unstabilized Approaches: A Phenomenology Study of the Risk Perceptions and Decision-Making Thought Process of Collegiate Aviation Pilots
}

\author{
Shlok Misra, Jorge L.D. Albelo, and Victor Fraticelli Rivera \\ Embry-Riddle Aeronautical University
}

\begin{abstract}
The Federal Aviation Administration emphasized the need to focus on and develop human factors training as early as 1993 in official Human Factors Policy Order 9550.8. The purpose of this study was to conduct a detailed qualitative phenomenological analysis of the risk perceptions and decision-making model of collegiate aviation pilots for unstabilized approaches. The study focused on understanding how collegiate aviation pilots perceive unstable approaches, the risk associated with unstable approaches, and the factors that trigger pilots to execute a go-around. The International Air Transportation Association warns that continuing an unstabilized approach can lead to runway excursions, hard landings causing damage to aircraft, or even controlled flight into terrain. The theoretical framework guiding this study was the risk compensation theory. The researchers recruited 15 participants through purposeful sampling for a phenomenological analysis using semi-structured interviews and a short questionnaire. A phenomenological methodology enabled the researchers to bring forth into consciousness preconceived ideas about unstabilized approaches and then set them aside. To address the research questions, information collected from individual interviews was analyzed and triangulated using a qualitative questionnaire. Three major themes emerged from the data: (a) effect of internal perceptions, (b) external pressures, and (c) unique worldviews. The findings validated the risk compensation theory's principles by exposing the influence of mental and environmental factors impairing participants' judgment of an unstabilized approach. Further research is required for developing standardized and objective stabilization criteria that the general aviation community can accept.
\end{abstract}

Keywords: aeronautical decision-making, flight training, general aviation, phenomenology, risk perception, unstabilized approach

\section{Introduction}

Human factors research has been considered a vital component to continuously improve aviation safety in the United States. The Federal Aviation Administration (FAA) identified the need to invest in human factors to improve safety and published its official Human Factors Policy Order 9550.8 (FAA, 1993). The Human Factors Policy Order 9550.8 emphasized the need for "incorporating and coordinating human factors considerations" in the research and development, programs, and activities that were focused on enhancing "aviation safety, efficiency, and productivity" (FAA, 1993, p. 1). The FAA emphasized the need for human factors research to analyze existing systems and identify threats that could be mitigated through research, 
development, and engineering (FAA, 1993). With growing air traffic and the expansion of the general aviation industry, there is a growing need for research that is focused on human factors in general aviation pilots.

The purpose of this study is to conduct a detailed qualitative phenomenological analysis of the risk perceptions and decision-making model of collegiate aviation pilots for unstabilized approaches. The study focuses on understanding how collegiate aviation pilots perceive unstable approaches, the risk associated with unstable approaches, and the factors that trigger pilots to execute a go-around. Embry-Riddle Aeronautical University (ERAU), Daytona Beach Campus, was the research site used to collect the data. This research study was sponsored by the ERAU College of Aviation Philanthropy Council.

\section{Statement of the Problem}

Unstabilized approaches pose a major risk for pilots. The International Air Transportation Association (IATA) warns that continuing an unstabilized approach can lead to runway excursions, hard landings causing damage to aircraft, or even controlled flight into terrain (IATA, 2016). The Flight Safety Foundation's International Advisory Committee (IAC) explained that often pilots did execute go-arounds in spite of flying an unstable approach to landing below the stable approach height as mandated by the standard operating procedures of the operator they were flying for (Blajev \& Curtis, 2017). This discussion, initiated by the IAC, led the Flight Safety Foundation to invest in research and development that focused on the unwillingness of pilots to execute go-around maneuvers despite flying unstable approaches. There is a need for further research on the risk perception of pilots and the unwillingness to go-around. While significant research has been conducted on risk perception and unstabilized approaches for commercial and airline pilots, there is a significant research gap on understanding risk perception and unwillingness to go-around for general aviation pilots. Collegiate flight training programs are significant stakeholders in the general aviation community that provide flight training to students that are likely to seek a career in commercial or airline flying. This study will utilize collegiate aviation pilots for the analysis. The research questions guiding this study are:

- How do collegiate aviation pilots perceive risks associated with unstable approaches?

- What factors contribute to unstable approaches as perceived by collegiate aviation pilots?

\section{Significance of the Study}

Increasing safety in aviation is of interest to all stakeholders in the National Airspace System. This study focuses on collegiate aviation pilots and their perception of risk associated with unstable approaches based on their lived experiences. The results of this study are significant to human factors researchers and specialists, the FAA, flight training organizations, and other stakeholders of the National Airspace System. This study aims to bridge the research gap on understanding risk perception and decision-making of general aviation pilots. While the general aviation pilot population is extremely diverse, collegiate flight training programs are significant stakeholders in the general aviation community that train students that are likely to seek a career as professional pilots. While this study's results will be specific to the collegiate aviation pilot population, this study's data can be utilized to develop a literature foundation for further research on the larger general aviation population. Flight training organizations and flight instructors can also use this study's data to modify or create instructional material.

\section{Literature Review}

Human error is a major component of aviation accidents, and $70-80 \%$ of accidents are caused by some human error (Wiegmann \& Shapell, 2003). Gong et al. (2014) analyzed the role of human factors in aviation accidents and proposed an integrated graphic-taxonomic-associative approach to analyzing aviation accidents, and identified human factors as "critical causes of modern aviation accidents" (Gong et al., 2014, p. 1). The proposed accident analysis approach highlighted the role of human factors in analyzing and identifying unsafe factors that led to accidents.

\section{Unstable Approaches}

The approach phase of a flight is a safety-critical component of every flight. The IATA stated that $65 \%$ of all commercial aircraft accidents from 2011 to 2015 occurred during the flight approach (IATA, 2016). For accidents recorded from 2011 to2015, an unstable approach was analyzed as a factor for $14 \%$ of the accidents. The IATA stated that poorly executed approaches and a failure to execute go-arounds are contributory factors to many accidents in commercial aviation. Similar to the findings of IATA (2016), the FAA Aviation Safety Team (FAASTeam) published a fact sheet on stabilized approach and landings that emphasized the need for establishing and maintaining a stable approach to reduce the risk of loss-ofcontrol accidents. The FAA stated the need for a pilot to maintain the judgment of visual cues to maintain a stable approach (FAASTeam, n.d.).

\section{Stable Approach Concept}

The FAA has published a standard stable approach concept in Chapter 8 of the Airplane Flying Handbook 
(FAA, 2016). The FAA states that the pilot must establish and maintain a "constant angle glide path towards a predetermined point on the landing runway" (FAA, 2016, p. 8-9). The FAA emphasizes the need for a constant rate of descent and constant airspeed on final approach. Additionally, the FAA emphasizes the need to adopt an "aiming point" and the visual references for a pilot to judge a stabilized approach (FAA, 2016, p. 8-9). The FAA also emphasized the need for a go-around when a stable approach cannot be executed. The FAA advised instructor pilots to communicate the idea that a go-around can be executed at any time during the approach to the landing phase.

The FAA identifies two major factors that inhibit pilots from continuing an unstable approach and not executing a go-around maneuver (FAA, 2016). Landing expectancy or set is defined as the "anticipatory belief that conditions are not as threatening as they are and that the approach is surely terminated with a safe landing" (FAA, 2016, p. 8-13). The concept of landing expectancy is also discussed by Cox (2015) in an article titled "Go-around: The sooner, the better." The concept of landing expectancy explains that a pilot executing an unstable approach might be aware that the approach is unstable, but an inherent bias or belief tends the pilot to believe that the threats associated are not worthy of executing a go-around and that a safe landing can be executed (Cox, 2015). There is a lack of literature that explains the factors that increase the tendency of a pilot to exhibit landing expectancies, such as flight experience, age, gender, or cultural background. However, landing expectancy is an important human factors concept as it explains that even though a pilot might be aware that the approach is unstabilized, they might continue the approach and not execute a go-around by either ignoring the risks or downsizing them.

The second factor identified by the FAA that inhibits a pilot from executing a go-around is pride. The FAA defines pride as "the mistaken belief that the act of going around is an admission of failure-failure to execute the approach properly" (FAA, 2016, p. 8-13). Pilots may perceive executing a go-around as an act of failure or delegitimizing their proficiency as a pilot. There is a lack of literature on the factors that increase a pilot's likelihood of exhibiting pride, such as age, flight experience, gender, or cultural background.

The Flight Safety Foundation published an Approach and Landing Accident Reduction Briefing Note 7.1 that focused on the concept of stabilized approaches. The Flight Safety Foundation (2009) explained some of the factors that lead to unstabilized approaches. Pilot fatigue, psychological pressures, automation dependency, visual illusions, and air traffic control instructions were identified as some factors that lead to unstable approaches. Additionally, the Flight Safety Foundation stated that "belief that the aircraft will be stabilized at the minimum stabilization height" and "excessive confidence by the PNF/PM [pilot monitoring] that the P.F. [pilot flying] will achieve a timely stabilization" were two factors leading to unstabilized approaches (Flight Safety Foundation, 2009, p. 2).

\section{Psychological Factors Preventing Pilots from Executing Go-Around Maneuvers}

Research suggests that pilots' hesitancy to execute goaround is rooted in psychological factors. Blajev and Curtis (2017) analyzed "the psychology of non-compliance" (p. 3). Blajev and Curtis (2017) stated that pilots consider executing the go-around maneuver as risky due to the lack of experience of executing go-arounds and the go-around maneuver is a rare maneuver for many pilots, which gives rise to fear for executing the maneuver. Blajev and Curtis (2017) recommended that the definition of a stable approach be updated with more objective parameters. Furthermore, it is important to develop and enhance the decision-making criteria used to assess a stable approach and that "decision making is viable beyond the defined approach phase" (Blajev \& Curtis, 2017, p. 4). There is also a need for further research on developing pilots' situation awareness that influences decision-making during an approach. The findings of the report suggested that a pilot's behavior and actions are functions of a decisionmaking process which is influenced by various external and internal factors and that situation awareness plays a key role in influencing the way pilots perceive these factors. The external and internal factors also influence a pilot's perception of risk and risk tolerance (Blajev \& Curtis, 2017).

Similar to the approach taken by Blajev and Curtis (2017), Lai et al. (2019) studied unstable approaches in aviation from the perspective of shared mental models of pilots. Lai et al. (2019) focused on pilots' decision-making and performance that lead to continuing unstabilized approaches and not executing go-around maneuvers. Lai et al. (2019) studied the role of increased workload on the pilot, leading to impaired decision-making during an approach. Lai et al. (2019) also focused on the role of continuation bias, which is a form of cognitive bias that leads a pilot into continuing an unstable approach. Cognitive bias occurs when "human cognition reliably produces representations that are systematically distorted compared to some aspect of objective reality" (Fong et al., 2017 , p. 1). It can quite simply be described as a systematic error in thinking and judgment that affects the decisions humans make. Cognitive bias is a "pattern" where humans selectively process information presented (Kuckertz \& Amir, 2017, p. 1). Elston (2019) explains cognitive bias as a sophisticated filter developed by the brain that allows us to focus on information that our brain perceives to be important to us and dampen input that we do not perceive to be important. 
Situation Awareness and Unstable Approaches

Situation awareness of a pilot influences their perception of threats and risks during all phases of flight. The FAA (2016) discusses the role of situation awareness in the Pilot's Handbook of Aeronautical Knowledge. The FAA describes situation awareness as "the accurate perception and understanding of all the factors and conditions within the five fundamental risk elements (flight, pilot, aircraft, environment, and type of operation that comprise any given aviation situation)" (FAA, 2016, p. 2-24). The FAA states that the concepts of aeronautical decision making (ADM), single-pilot resource management, and situation awareness are linked as they are key influencers of a pilot's perception and ability to manage risks (FAA, 2016). Some other factors that influence a pilot's ability to manage resources and maintain safety are task management, risk management, and automation management. Some obstacles to maintaining situation awareness include fatigue, stress, distractions, and task saturations (FAA, 2016). During the approach phase of flight, a pilot is likely to be fatigued as the approach and landing are executed at the end of the flight. A fatigued pilot is likely to lose situation awareness that will affect the pilot's decision-making process and risk perception. A pilot is most likely to be task-saturated when faced with a workload that is beyond psychological or physiological capabilities at a point in time. During an approach and landing, a single pilot might be looking out for traffic, maintaining visual contact with the runway environment, contacting air traffic control, tuning in radio frequencies, and operating the aircraft in a busy airspace. This phase of flight presents a high workload, which can alter a pilot's resource management and decision-making.

The FAA states that situation awareness "enables the pilot to assess and manage risk and make accurate and timely decisions" (FAA, n.d.). The FAASTeam emphasizes the need for sufficient ADM skills to maintain situation awareness. The FAASTeam states that "understanding the decision-making process provides a foundation for developing the necessary ADM skills" (FAA, n.d., p. 1). The pilot's ADM skills and risk perception influence the decision-making model of the pilot. Some of the processes involved in decision-making are defining the problem, choosing a course of action, and assessing the risk elements of a situation. O'Brien and O'Hare (2007) studied the role of situation awareness ability in successful performance by human beings at dynamic realworld tasks. O'Brien and O'Hare (2007) stated that perception, memory, attention, and executive control are abilities that underline the attainment of situation awareness, which impacts a person's performance in dynamic environments. O'Brien and O'Hare's statements are extended from the work of Endsley (1988) on situation awareness, who proposed a hierarchical model of situation awareness.

\section{Risk Perception}

The FAA states that hazards and risks are "two defining elements" of ADM (FAA, 2016, p. 2-4). The FAA Risk Management Handbook defines a hazard as "a hazard is a present condition, event, object, or circumstance that could lead to or contribute to an unplanned or undesired event such as an accident" (FAA, 2009, p. 1-2). The FAA defines risk as "the future impact of a hazard that is not controlled or eliminated" (FAA, 2009, p. 1-5). An important component of aviation safety is identifying hazards and managing risks.

Risks from a hazard can be perceived differently by people. Risk perception is a personal process that differs from person to person (Brown, 2014). The risk perception process is influenced by a person's surroundings, mental state, and personal background amongst a range of other factors (Brown, 2014). The perception of risk is subjective as the same hazard can be interpreted differently by different people at different times and places (Ropeik, 2012). An effect of this subjectivity is the "risk perception gap" which is the "gap between our fears and the evidence" (Ropeik, 2012, p. 1). Humans might tend to either upsize or downsize a threat that might not be consistent with the evidence that might be present regarding the severity of a present hazard. This risk perception gap arises because risk perception is largely an "unconscious emotional process" (Brown, 2014, p. A277). This gap leads to humans forming decisions based on the perception gaps that can influence the decision-making process. Ropeik (2012) explains that it is important to understand how an individual perceives risk and the perception gap formed. The understanding of the perception gap is important "to recognize the dangers that can arise when we sometimes get risk wrong, and in order that we may more wisely manage those risks" (Ropeik, 2012, p. 1). Wachinger et al. (2013) stated that it is important to analyze the process of humans perceiving risks because the perception of risk is different from the perception of other real phenomena such as sight and sound, as humans do not fundamentally use sense organs for risk perception. Risk perception is an internal process through "mental models" that a person utilizes to "judge risks" (Wachinger et al., 2013, p. 1049). These mental models are influenced by cultural backgrounds, learning, and experience, amongst a range of other factors. Additionally, these mental models utilized to judge risks are "constantly moderated" which can include reinforcement, modifications, amplification, or attenuation (Wachinger et al., 2013, p. 1049). These mental models affect the perception of risk, which can differ for different types of risks, the context in which the risk is presented, and the social understanding and background of the person. Wachinger et al. (2013) explained the role of risk perception in the actions a person takes as risk perception is influenced by past experiences, information received from stimuli, and possible external pressures and 
peer pressure. Additionally, the perception of risk can also be affected by "intervening variables" such as a person's ability to handle a particular situation, economic conditions, and trust and responsibility (Wachinger et al., 2013, p. 1054). The risk perception has a direct effect on the "preparedness" and "willingness to act" which leads to a person's actions (Wachinger et al., 2013, p. 1054).

\section{Implications of Risk Perception on Unstable Approaches}

The literature review has focused on factors identified by previous scholarly studies that lead to an unstabilized approach with a focus on the psychological factors that affect a pilot's decision or noncompliance to stable approach criteria. Blajev and Curtis (2017) addressed the concerns of pilot unwillingness to execute go-around maneuvers with a variety of reasons, which included lack of situation awareness and the role of risk perception. The Flight Safety Foundation's analysis corresponded to the phenomenon of landing expectancy that the FAA has illustrated in the Airplane Flying Handbook. Literature concerning situation awareness and risk perception was reviewed to gain a fundamental understanding of the decision-making process used by human beings in dynamic situations. The literature review revealed that the situation awareness of a pilot has a direct effect on the way a human perceives risk and makes decisions. Humans tend to perceive risks differently, which is influenced by culture, time and context, and training and experience, amongst various other factors. The risk perception process directly impacts the decision-making model of human beings.

The literature review addresses the role of situation awareness and risk perception in influencing a pilot's decision-making during an approach. The approach phase of a flight is a work-intensive phase of flight that external pressures and fatigue can characterize. A pilot is exposed to various physical stimuli outside the aircraft (visual references) and inside the aircraft (instrumentation). A pilot relies on these references and instrumentation to judge the risks and make decisions.

\section{Theoretical Framework}

The theory guiding this study was the risk compensation theory. The risk compensation theory's roots can be traced back to the risk homeostasis theory, which was originally used in the mid-1800s in physiology by Bernard and then later used by Cannon in the early 1900s (Trimpop, 1996). The term "homeostasis" was initially used to define body processes such as blood pressure, temperature, and respiration rate. The risk homeostasis theory stated that there was a specific value for each action and, therefore, could be described as a constant value. Consequently, the fluctuation process between the values or the target level was referred to as homeostasis. In 1976, Gerald Wilde formalized this notion by a formation of a model of driver behavior (Trimpop, 1996). Wilde named this formation the "risk compensation theory." The theory is based on the compensating actions that are triggered by the perception of the discrepancy between the observed and desired level of risk (Trimpop, 1996). In other words, the theory hypothesizes that people compare the amount of risk perceived with their target level of risk and, in an attempt to eliminate the discrepancy between the observed and desired level of risk, individuals will adjust their behavior (Wilde, 1998).

The risk compensation theory has been predominantly used in the transportation industry during the development of safety features such as the seatbelt and the antilock braking system. Wilde's (1998) theory of compensation proposes that the introduction of external safety measures can only reduce accidents until the driver perceives the consequences of the accident. However, Wilde's (1998) theory also suggested that once the driver notices the increase in safety features, the driver will feel safer and will adopt a riskier behavior in exchange for performance benefits such as getting to their destination in a shorter amount of time (Wilde, 1998). Wilde's response to the increase in accidents was to target the level of risk rather than the introduction of technical solutions. Therefore, if the perception of risk stays the same, the motivation to change behavior will also stay the same.

Ultimately, the target level of risk will depend on the perception of the costs, and the benefits of behavioral alternatives of either being safe or assuming risky behavior. Wilde (1998) believes that the target level of risk will drop if the value of cautious behavior (incentives), and the negative consequences of risky behavior (punishment), is increased compared to the decrease in the benefits of risky behavior (heroism) and the negative consequences of cautious behavior (time loss). The lower value of the target level will lead individuals to drive more cautiously by reducing their speed and paying more attention to the road.

Similar to other means of transportation, the aviation industry shares human intervention as a common denominator in the risk perception area. Pilots are susceptible to risk compensation and in the engagement of behavioral change due to the ability of the pilot to perceive risk. This risk perception was evidenced by Hunter (2002) in his study in conjunction with the U.S. Department of Transportation and the FAA called Risk Perception and Risk Tolerance in Aircraft Pilots. According to Hunter (2002), pilots with a low perception of risk tend to be involved in more hazardous events. Consequently, risk misperception is associated with exposure to hazardous aviation events. A higher level of pilot experience and qualification was associated with a lower level of perceived risk excluding student pilots who experience a lower risk estimation in aviation. Hunter (2002) concludes that this lower risk estimation is due to a lack of knowledge and sufficient understanding of how to estimate risk. 
Inappropriate assessment of risk perception was also considered by Orasanu et al. (2002) in their study called Risk Perception: A Critical Element of Aviation Safety.

According to Orasanu et al. (2002), the error in the assessment of risk perception reflected on the familiarity with and experience of the threat and how the individual is affected by potential negative consequences, how imminent the consequences are, and the perception or sense of control over the situation. The inappropriate assessment of risk occurred due to a pilot's underestimation of the risk in a dynamically changing situation and the pilot's estimation of their ability to deal with the perceived risk resulting in believing that they are more skilled or in control of the situation (Orasanu et al., 2002). The pilots in the study were adopting alternate plans of action when they perceived that a particular risk was close to or beyond their comfort zone. In other words, the pilots were perceiving the risk and modifying the actions to reach their desired or target level of risk. This behavior modification validates the foundation of the risk perception and compensation theory.

\section{Methodology}

This phenomenology study aimed to understand the risk perceptions and decision-making skills of Embry-Riddle Aeronautical University students in training related to judging unstabilized approaches based on their lived experiences.

\section{Participation}

All participants, at the time of this study, were matriculated to Embry-Riddle Aeronautical University's Daytona Beach residential campus to earn their bachelor's degree. Ten of the 15 participants were in the aeronautical science program, while the other five were in the aeronautics program. Twelve participants had plans of pursuing an airline pilot career, while the other three hoped to pursue an aviation career in the private sector. The participants were required to be at least 18 years old and possess a private pilot, commercial pilot, or flight instructor certificate. The researchers interviewed a total of 15 participants, five of which were private pilots, five were commercial pilots, and five were flight instructors. The purpose of such a sampling strategy was to gather data from a wide spectrum of flight experience that is available in a collegiate flight program. The samples (private pilots to flight instructors) were expected to have sufficient prior knowledge on stabilized approaches and the aircraft procedures (Cessna 172 Skyhawk) that were simulated in the study. The participants' demographics and pseudonyms are shown in Table 1.

\section{Scenarios and Questions}

The three approach scenarios utilized for this study were recorded on a RedBird Advanced Aviation Training Device for a Cessna 172 Skyhawk Nav III. The Cessna 172 Skyhawk was the same aircraft used by the participants for the single-engine flight training at the university and the participants were expected to be familiar with basic operating characteristics of the aircraft and indications on the Primary Flight Display. The interviews for the study were conducted through the Zoom video conference application due to Covid-19 and associated Institutional Review Board protocols of the university. The recordings of the scenarios were played during the virtual interviews. The participants were asked a total of 15 open-ended questions for the interview.

\section{Scenario 1}

The aircraft is approaching Runway 16 at Daytona Beach International Airport (KDAB). The aircraft is at 1000 feet above ground level (AGL) and is stabilized at the prescribed approach speed for the aircraft (65 knots).

Table 1

Participant demographics (pseudonyms)

\begin{tabular}{llll}
\hline Pseudonym & Age & Ethnicity & Academic-level degree \\
\hline Alex & 19 & White & Sophomore Aeronautical Science, BS \\
Thomas & 23 & White & Senior Aeronautical Science, BS \\
Christopher & 21 & Asian & Senior Aeronautical Science, BS \\
Michelle & 19 & White & Freshman Aeronautical Science, BS \\
Patrick & 22 & Asian & Masters Aeronautics, MS \\
Mikaela & 19 & White & Freshman Aeronautical Science, BS \\
Carolina & 21 & Hispanic & Senior Aeronautical Science, BS \\
Andrew & 22 & Senior Aeronautical Science, BS \\
Janet & 22 & White & Senior Aeronautical Science, BS \\
Bobby & 20 & Asian & Junior Aeronautical Science, BS \\
Mike & 19 & White & Sophomore Aeronautical Science, BS \\
Billy & 21 & White & Junior Aeronautical Science, BS \\
Hunter & 20 & White & Sophomore Aeronautical Science, BS \\
Jessica & 25 & Asian & Masters Aeronautics, MS \\
Colin & 23 & Asian & Masters Business Administration \\
\hline
\end{tabular}


The pilot inadvertently starts pitching the aircraft up without appropriate change in power. The aircraft's speed starts slowing down to 55 knots at around 300 feet AGL.

1) Based on your lived experiences, how would you determine your go-around decision?

Follow-up: Explain in detail your thought process (e.g., altitude, etc.)

2) What risks do you perceive if one were to continue the approach?

3) Describe the factors that influenced your decisionmaking to command a go-around.

\section{Scenario 2}

The aircraft is approaching Runway 16 at KDAB. The aircraft is at 1000 feet AGL and is extremely high on the approach with all four Precision Approach Path Indicator lights indicating that the aircraft is higher than the standard approach path. The pilot attempts to recover by pitching the aircraft down which leads to an increase in airspeed. The pilot is approaching the runway at 100 knots (35 knots above the prescribed approach speed) at 250 feet AGL.

4) Based on your lived experiences, how would you determine your go-around decision?

Follow-up: Explain in detail your thought process (e.g., altitude, etc.)

5) What risks do you perceive if one were to continue the approach?

6) Describe the factors that influenced your decisionmaking to command a go-around.

\section{Scenario 3}

The aircraft is approaching Runway 16 at KDAB. The aircraft is at 1000 feet AGL and is experiencing a 20 knots crosswind from the left. The pilot utilized faulty crosswind correction technique is deviating off the lateral approach path. The pilot is recovering by banking the aircraft up to 20 degrees at 200 feet.

7) Based on your lived experiences, how would you determine your go-around decision?

Follow-up: Explain in detail your thought process (e.g., altitude, etc.)

8) What risks do you perceive if one were to continue the approach?

9) Describe the factors that influenced your decisionmaking to command a go-around.

\section{Open-Ended Questionnaire}

10) Please describe the concept of a stabilized an approach.

11) How do you perceive having a co-pilot/flight instructor could influence your perceptions of risks associated with continuing an unstabilized approach?

12) What techniques would you use to attempt "saving" the landing?

\section{Procedures}

This research used a purely qualitative approach to understand the risk perception and the decision-making skills of collegiate aviation pilots related to unstabilized approaches based on their lived experiences. The use of a phenomenology methodology enabled the researchers to bring forth into consciousness preconceived ideas about unstabilized approaches and then set them aside (Creswell, 2013; Moustakas, 1994). According to Conklin (2014), phenomenology aspires to dive into the personal and individual perceptions within themes. Furthermore, this methodology enabled researchers to access knowledge that is particular, a kind of knowledge that offers insight into idiosyncrasy. Therefore, by accessing this knowledge, researchers were able to study individuals' insights and interpretations of their lived experiences, which cannot otherwise be accessed. However, Moustakas (1994) strongly suggests bracketing out the researchers' feelings and opinions through the data analysis so that the findings are limited to the themes that emerged from the participants' experiences. Individual interviews were the primary data source, but additional data were retrieved from a short qualitative questionnaire to gain further information based on the scenarios presented and to achieve triangulation of the data. The researchers followed Patton's (2015) interview guidelines to "ensure that the same basic lines of inquiry [were] pursued with each person interviewed" (p. 439). One of the main advantages of Patton's (2015) interview guides is that they enabled the researchers to interview all participants in a systematic and comprehensive manner that delimited the issues to be explored in advance. Interviews were audio-recorded and transcribed for accuracy. The participants were presented with three video-recorded scenarios to evaluate. A short qualitative questionnaire was used to understand how their perceptions play a role in determining an unstabilized approach. Once the data were collected and transcribed, they was sent to the participants for review and accuracy assurance.

\section{Data Analysis}

While several data analysis methods could be used to obtain a clear understanding of the phenomenon in question, bracketing, phenomenological reduction, and composite textural and structural descriptions were the most appropriate data analysis procedures for this study to ensure the essence of the experience of the participants is truly captured. Moustakas (1994) defines bracketing as being transparent with ourselves "to allow whatever is before us in consciousness to disclose itself" so that the researcher can view context through a different lens with an open mind (p. 86). Therefore, researchers had to bracket their thoughts with an open mindset to focus on the participants' lived experiences. To assist in successfully 
bracketing ideas, the researchers kept reflective notes to help uphold transparency and reduce research bias. According to Creswell (2013), this process allows researchers to discard preconceived perspectives and achieve confirmability.

Following Moustakas's (1994) data analysis steps, phenomenological reduction enabled the researchers to describe the participants' textural language and meaning. The researchers' job was to continuously look for textural attributes and descriptions within the data related to the phenomenon with an experiential reference. Lastly, because the phenomenon in question happened in a specific time and place, composite and structural descriptions provided a "unified statement of essences of the experience of the phenomenon as a whole" (Moustakas, 1994, p. 100). Because all interviews were transcribed, open coding was used to create categories around the core phenomenon (Creswell, 2013). Furthermore, axial coding was used to relate themes to the core phenomenon. Axial coding assisted with the confirmation of the themes represented from the data collected and created a more exact identification of the essential components (Conklin, 2014; Creswell, 2013).

\section{Findings}

To address the research questions, information collected from individual interviews was analyzed and triangulated with the use of a qualitative questionnaire. As code began to saturate, themes began to emerge from the data, expressing how the participants' lived experiences related to the risk perception and the decision-making skills towards unstabilized approaches. There were three major themes that emerged from the data: (a) internal perceptions, (b) external pressures, and (c) unique worldview.

\section{Theme 1: Internal Perceptions}

Internal perception is the first major theme that emerged from the findings. Internal perception refers to the participants' insights and observations, towards a flight instructor or an additional crewmember, during a visual approach and landing. The findings supported that participants' internal perception affects their risk and safety discernment during a visual approach and landing. As a result, participants were willing to accept a higher-thannormal level of risk. These findings have theoretical implications as they validate the theory that people compare the amount of risk perceived with their target level of risk and, as an attempt to eliminate the discrepancy between the observed and desired level of risk, individuals will adjust their behavior (Wilde, 1998).

In this study, the participants revealed that their willingness to continue an unstabilized approach was influenced by their internal perceptions of a flight instructor or crewmember. Participants were tolerating a higher level of risk (continuing an unstabilized approach) by relying on the other crewmember's experience and contributions during the approach phase. For example, one participant expressed, "I feel that I'm at a lot less risk with another copilot or flight instructor on board and I'm most likely going to continue the approach lower than I would if I was just by myself. I'm going to go around sooner [sic] rather than I am fine [sic] with another flight instructor or someone I know then I'll be more comfortable continuing lower on approach, even if it is unstabilized." Another participant synthesized this notion when sharing their experiences in unstabilized approaches, "I ask myself if my instructor will support me. Are they going to back me up or will they going to question me or ridicule me?" Though they expressed hesitation, participants' actions correlate with Wilde's (1998) theory of risk compensation as they used the instructor's experience and contributions as a safety feature and were inclined to adopt a riskier behavior and continue the unstabilized approach. Another participant expressed, "[flight instructors] have enough hours, and been through enough to where they probably understand [if an approach] is stable or very unstable." Other participants communicated that having an additional crewmember is perceived as an increased level of safety which influenced their perceived level of risks. For example, one participant stated, "I think it definitely helps. I mean, two people behind the controls is a lot safer than one, you have a second set of eyes to watch for a host of you know, good or bad things that you can notice. So, I'd say it influences a pilot in a good way to have a second set of eyes." The findings validate the risk compensation theory since participants perceived that being on board with a flight instructor or an additional crewmember influenced their decisions to continue an approach and to accept a higher level of risk. Consequently, participants were adopting a riskier behavior due to the perception that an additional crewmember compensates for a high level of risk.

In relation to aviation safety, recognizing individual thinking practices and the decision-making process can be closely related to analytical modes. Based on the findings, internal perception contributes to a pilot's rationality to choose among alternatives based on how they are perceived. The sense of being judged that all participants expressed shows empirical implications as these mental models used to judge risks are "constantly moderated" which can include reinforcement, modifications, amplification, or attenuation (Wachinger et al., 2013, p. 1049). Evidently, internal perception is the number one factor contributing to the negative impact of external pressures.

\section{Theme 2: External Pressures}

Aside from internal perceptions, particularly hesitation, the second theme that emerged from the data was external pressures. Participants in this study felt that external 
pressures, such as due-back times and low altitudes, influenced their perceptions and decision-making process related to unstabilized approaches. One participant expressed, "[although] we have tight tolerances at low altitudes, I find myself saving the landing especially when faced with an operational pressure like due back times." Most participants felt that relying on confidence, even if the actions taken are not procedurally correct, enables them to "save the landing" to meet external pressures. There are two empirical implications in which external pressures seem to interfere with the decision-making process in an unstable approach situation: perception of risk and situation awareness. While the risk perception process is influenced by a person's surroundings, mental state, and personal background amongst a range of other factors (Brown, 2014), the data from this study validate that both mental state and the surroundings directly interfere in how an unstabilized approach is judged.

On the other hand, participants perceived low altitudes as an external pressure that influenced their decision to reject a landing. The majority of the participants agreed that safety margins "tightened" as altitude decreases in an approach to land. However, though safety margins decrease, participants from this study seem to let external pressure influence their rationale when they are judging an unstabilized approach. The participants' lived experiences validate the theoretical implication that if the perception of risk stays the same, the motivation to change behavior will also stay the same (Wilde, 1998).

\section{Theme 3: Unique Worldview}

The last theme that emerged from the data was a sense of unique worldview. The participants in this study acknowledge numerous factors perceived as a risk (e.g., hard landings, flap overspeed, stalls), though they are willing to overlook them in an effort to correct an unstabilized approach. For example, one participant noted that an unstabilized approach would lead to "damage [of] the breaks, airframe, and wheels. [Even] stalling a few hundred feet before the runway" if proper corrections are not made. Another participant shared that in their experience, "forcing an approach lead to overshooting the runway, [a] hard landing or potentially worse." These statements validate the claims by Blajev and Curtis (2017) that pilots consider executing the go-around maneuver as risky due to the lack of experience of executing go-arounds and the goaround maneuver is a rare maneuver for many pilots, which gives rise to fear for executing the maneuver.

As noted in past studies, Elston (2019) explained how cognitive bias allows us to focus on information that our brain perceives to be important and dampen input that is not perceived to be important. Data from this study show how participants are willing to give in to internal perceptions and external pressures, and, in turn, fall into complacency. For example, in a final approach scenario with Vapp significantly higher than calculated, participants recognized the "potential for overspending and damaging the flaps." Nevertheless, they are all collectively willing to save the landing as "there are less options and a higher risk if executing a go-around too late." The data further showed how their sense of complacency was directly tied to their worldview of risk and tolerances. Participants are "willing to take a higher risk due to tighter tolerances" at lower altitudes. The high sense of complacency found in the participants' lived experiences has significant theoretical implications. This notion of a high sense of complacency validates Hunter's (2002) claims that pilots with a low perception of risk tend to be involved in more hazardous events. Evidently, individuals' unique worldview could lead to unnecessary exposure to hazardous aviation events.

\section{Limitations}

There are multiple variations in how a phenomenological study is conducted (Patton, 2015). However, although generalizability cannot be achieved with the use of a small sample or a single site, the power of this qualitative research was strengthened with the use of purposeful sampling to derive information-rich cases. While the findings address the identified gap in the literature and are rooted in Wilde's (1998) theory of compensation, qualitative research data strive to describe, "capture and communicate someone else's experience of the world in his or her own words" (Patton, 2015 , p. 54)

\section{Discussion}

The purpose of this study was to conduct a detailed qualitative phenomenological analysis of the risk perceptions and decision-making model of collegiate aviation pilots for unstabilized approaches. The findings of this study highlighted the lack of objective stabilized approach criteria. IATA (2016) authenticated the notion of stabilized criteria with the recommendation of more objective-driven stabilization criteria for pilots to assist their decisionmaking to execute a go-around. These parameters need to be standardized in a flight training environment that ensures an easy transition when pilots receive instruction or operate with different pilots or instructors. Further research is required for developing standardized and objective stabilization criteria that can be accepted by the general aviation community. Perhaps it will be useful to conduct further research to root the definition of aviation skills in situation awareness. Moreover, this study's findings highlighted the need for the development of training aids that are focused on training pilots for identifying unstabilized approaches. While there is a variety of flight training devices, commonly referred to as 
flight training simulators, there is a need for the development of objective-driven visual training aids integrated with flight training device scenarios that would help pilots in the recognition of unstabilized approaches.

The factors associated with internal perceptions and external pressures suggested that students are prone to complacency. Although participants acknowledged many factors being perceived as risks (e.g., hard landings, flap overspeed, stalls), they are willing to overlook these factors to save an unstabilized approach based on their unique worldview. Despite the risks associated with an unstabilized approach, students are inclined to adopt a higher level of risk to compensate for adverse repercussions, including arriving late. The influence of mental and environmental factors impairing participants' judgement of an unstabilized approach validates the principles of the risk compensation theory. As a result, flight schools should consider the development of a one-day landing clinic delivered to every student. The one-day landing clinic could consist of analyzing students' internal decision-making process through continuous assessment of students' risk perception at different stages of the approach.

\section{References}

Blajev, T., \& Curtis, W. (2017). Go-around decision-making and execution project. Final report to the Flight Safety Foundation. https://flightsafety.org/wp-content/uploads/2017/03/Goaround-study_ final.pdf

Brown, V. (2014). Risk perception: It's personal. Environmental Health Perspectives, 122(10), A276-A279. https://doi.org/10.1289/ehp.122A276

Conklin, T. A. (2014). Phenomenology redux: Doing phenomenology, becoming phenomenological. Organization Management Journal, 11(2), 116-128. https://doi.org/10.1080/15416518.2014.929935

Cox, B. (2015). Go-arounds: The sooner, the better. Plane and Pilot, 51(7), 64-68.

Creswell, J. W. (2013). Qualitative inquiry and research design: Choosing among five approaches (3rd ed.). Sage Publications.

Elston, D. (2019). Cognitive bias and medical errors. Journal of the American Academy of Dermatology, 81(6), 1249. https://doi.org/10. 1016/j.jaad.2019.06.1284

Endsley, M. (1988). Situation awareness global assessment technique (SAGAT). In Proceedings of the IEEE 1988 National Aerospace and Electronics Conference (Vol. 3, pp. 789-795). IEEE. https://doi.org/ 10.1109/NAECON.1988.195097

FAA Safety Team. (n.d.). Stabilized approach and landing. FAA Aviation Safety. https://www.faa.gov/news/safety_briefing/2018/media/SE_ Topic_18-09.pdf

Federal Aviation Administration. (n.d.). Situational awareness. Course: ALC-408: ADM for LTA Free Balloons. https://www.faasafety.gov/ gslac/ALC/course_content.aspx?cID $=408 \& s I D=649 \&$ preview $=$ true

Federal Aviation Administration. (1993). Human Factors Policy Order 9550.8. https://www.faa.gov/documentLibrary/media/Order/9550.8.pdf
Federal Aviation Administration. (2009). Chapter 1: Defining elements of risk management. Risk management handbook. https://www.faa.gov/ regulations_policies/handbooks_manuals/aviation/media/faa-h-8083-2. pdf

Federal Aviation Administration. (2016). Pilot's handbook for aeronautical knowledge. https://www.faa.gov/regulations_policies/handbooks_ manuals/aviation/phak/media/04_phak_ch2.pdf

Flight Safety Foundation. (2009). Stabilized approaches. Flight Safety Foundation Briefing Note 7.1. https://www.skybrary.aero/bookshelf/ books/864.pdf

Fong, D., Fong, L., \& Chark, R. (2017). The bias of size in gambling decisions: Evidence from a casino game. Cornell Hospitality Quarterly, 59, 1. https://doi.org/10.1177/1938965517730313

Gong, L., Zhang, S., Tang, P., \& Lu, Y. (2014). An integrated graphictaxonomic-associative approach to analyze human factors in aviation accidents. Chinese Journal of Aeronautics, 27(2), 226-240. https://doi. org/10.1016/j.cja.2014.02.002

Hunter, D. (2002). Risk perception and risk tolerance in aircraft pilots. FAA Office of Aerospace Medicine. https://citeseerx.ist.psu.edu/ viewdoc/download?doi $=10.1 \cdot 1.81 .6803 \& \mathrm{rep}=$ rep1\&type $=$ pdf

International Air Transportation Association. (2016). Unstable approaches. Risk mitigation policies, procedures, and best practices (2nd ed.). https:// www.iata.org/contentassets/b6eb2adc248c484192101edd1ed36015/ unstable-approaches-2016-2nd-edition.pdf

Kuckertz, J. M., \& Amir, N. (2017). Cognitive bias modification. In S. G. Hofmann \& G. J. G. Asmundson (Eds.), The science of cognitive behavioral therapy (pp. 463-491). Elsevier Academic Press. https://doi. org/10.1016/B978-0-12-803457-6.00019-2

Lai, H., Chen, C., Kboo, L., \& Zheng, P. (2019). Unstable approach in aviation: Mental model disconnects between pilots and air traffic controllers and interaction conflicts. Reliability Engineering \& System Safety, 185, 383-391. https://doi.org/10.1016/j.ress.2019.01.009

Moustakas, C. (1994). Phenomenological research methods. Sage Publications.

O'Brien, K., \& O'Hare, D. (2007). Situational awareness ability and cognitive skills training in a complex real-world task. Ergonomics, 50(7), 1064-1091. https://doi.org/10.1080/00140130701276640

Orasanu, J., Fischer, U., \& Davison, J. (2002). risk perception: A critical element of aviation safety. IFAC Proceedings Volumes, 35(1), 49-58. https://doi.org/10.3182/20020721-6-ES-1901.01639

Patton, M. (2015). Qualitative research \& evaluation methods (4th ed.). Sage Publications.

Ropeik, D. (2012). The perception gap: Recognizing and managing the risks that arise when we get risk wrong. Food and Chemical Toxicology, 50(5), 1222-1225. https://doi.org/10.1016/j.fct.2012.02. 015

Trimpop, R. (1996). Risk homeostasis theory: problems of the past and promises of the future. Safety Science, 22(1-3), 119-130. https://doi. org/10.1016/0925-7535(96)00010-0.

Wachinger, G., Renn, O., Begg, C., \& Kuhlicke, C. (2013). The risk perception paradox-Implications for governance and communication of natural hazards. Risk Analysis, 33(6), 1049-1065. https://doi.org/10. 1111/j.1539-6924.2012.001942.x

Wiegmann, D., \& Shappell, S. (2003). A human error Approach to aviation accident analysis. Ashgate Publishing.

Wilde, G. (1998). Risk homeostasis theory: An overview. Injury Prevention, 4(2), 89-91. https://doi.org/10.1136/ip.4.2.89 